\title{
Degradation of Lipids in Yeast (Saccharomyces cerevisiae) at the Early Phase of Organic Solvent-induced Autolysis
}

\author{
Michiko ISHIDA-ICHIMASA \\ Department of Biology, Faculty of Science, Ibaraki University, Bunkyo, Mito, Japan
}

Received May 30, 1977

\begin{abstract}
Initial stage of organic solvent-induced autolysis in yeast was studied with ${ }^{14} \mathrm{C}$-acetate labeled cells. In the case of toluene-induced autolysis, primary cell injury which was estimated by leakage of UV absorbing substances from cell accompanied rapid deacylation of phospholipids. Lysophospholipids did not occur during autolysis. When autolysis was induced by addition of ethyl acetate, phospholipids of yeast cells were not degraded so much. Ethyl acetate rather inhibited yeast phospholipase activity under the condition tested.
\end{abstract}

Several organic solvents have been used to initiate autolysis in yeast for the isolation of enzymes and other cell constituents. Some examples are the applications of chloroform or ethanol, toluene and ethyl acetate in the preparations of proteases, ${ }^{1)} \beta$-fructofuranosidase, ${ }^{2,3}$; and cytochrome $\mathrm{c}^{4)}$ respectively. Although it is well known that some organic solvents such as diethyl ether and ethanol stimulate enzymatic degradation of phospholipids, the mechanism of initiation of autolysis by organic solvents in yeast cells is not elucidated enough.

The present paper deals with the degradation of phospholipids at the early phase of organic solvent-induced autolysis in yeast and discusses the correlation between the initiation of autolysis and degradation of phospholipids.

\section{MATERIALS AND METHODS}

Organism and culture condition. $S$. cerevisiae Lindegren stock 8256 was used. The medium used was the nutrient medium designated $\mathrm{CM}$ by Iguti. ${ }^{5)}$ The cells were grown in $100 \mathrm{ml}$ of $\mathrm{CM}$ medium in the presence of $5 \mu \mathrm{Ci}$ of ${ }^{1.14} \mathrm{C}$ sodium acetate (s.a. $54.9 \mathrm{mCi} / \mathrm{m}$ $\mathrm{mol})$ at $30^{\circ} \mathrm{C}$ under reciprocal shaking and harvested at late exponential phase and suspended in $0.25 \mathrm{M}$ acetate buffer ( $\mathrm{pH} 4.0$ or 6.0 ) or $0.25 \mathrm{M}$ Tris- $\mathrm{HCl}$ buffer ( $\mathrm{pH}$ 6.5) after washed with the same buffer.

Organic solvent-induced autolysis. Toluene and cysteine $^{\text {b) }}$ or ethyl acetate were added at $0.1 \mathrm{ml} / \mathrm{ml}$ and $4 \mathrm{mg} / \mathrm{ml}$ or $0.1 \mathrm{ml} / \mathrm{ml}$, respectively, to the cell suspension (17 mg dry wt. of cells $/ \mathrm{ml}$ of various buffers) and the mixtures were incubated at $37^{\circ} \mathrm{C}$ under reciprocal shaking.
Extraction and analysis of lipids. The incubated mixtures were heated for $10 \mathrm{~min}$ in boiling water and sonicated twice for $5 \mathrm{~min}$ at $20 \mathrm{KC}$ in an ice bath. Then, lipids were extracted from the aqueous suspension by the procedure described by Bligh and Dyer. ${ }^{\text {? }}$

Appropriate amounts of extracted lipids were chromatographed on precoated thin-layer plates of silica gel 60 (without fluorescent indicator) (E. Merck Co.) with solvents of petroleum ether-diethyl ether-acetic acid $\left(80: 30: 1\right.$, by vol $\left.{ }^{8}\right)$ for neutral lipids, and chloroformmethanol-acetic acid-water (25:15:4:1, by vol.) for phospholipids. The identity of each lipid component was established by comparing the $R f$-value and the fluorescence visible in UV light of the spot with those of appropriate standard compounds and also by spraying the plates with ninhydrin, molybdenum ${ }^{9)}$ and Dragendorff reagent. ${ }^{10)}$ The spots on thin-layer chromatographic plates were detected under UV light after spraying with a $95 \%$ ethanol solution containing $0.2 \%$ $2^{\prime}, 7^{\prime}$-dichlorofluorescein ${ }^{11)}$ and scraped into scintillation vials and their radioactivity was measured by a Packard model 3380 Tri-carb liquid scintillation spectrometer with a model 544 absolute activity analyzer in a scintillation cocktail according to Okuyama and Wakil. ${ }^{12)}$

\section{RESULTS}

Lipid extraction from intact yeast cells is known to require some pretreatment such as freeze-drying, mechanical disintegration, enzymatic lysis of cell wall before extraction with organic solvents. ${ }^{13}$ ) The extent of lipids extracted also depends on culture conditions and the species of yeasts besides the extraction methods. Suzuki et al. ${ }^{14)}$ reported that only limited amount of lipids was extracted from intact yeast, Lipomyces starkeyi by a direct 
Table I. Comparison of Methods for Extracting Lipids

Lipids were extracted from $1 \mathrm{ml}$ of ${ }^{14} \mathrm{C}$-labeled cells of $S$. cerevisiae $(17 \mathrm{mg}$ dry $\mathrm{wt} . / \mathrm{ml})$ suspended in $0.25 \mathrm{M}$ acetate buffer (pH 6.0).

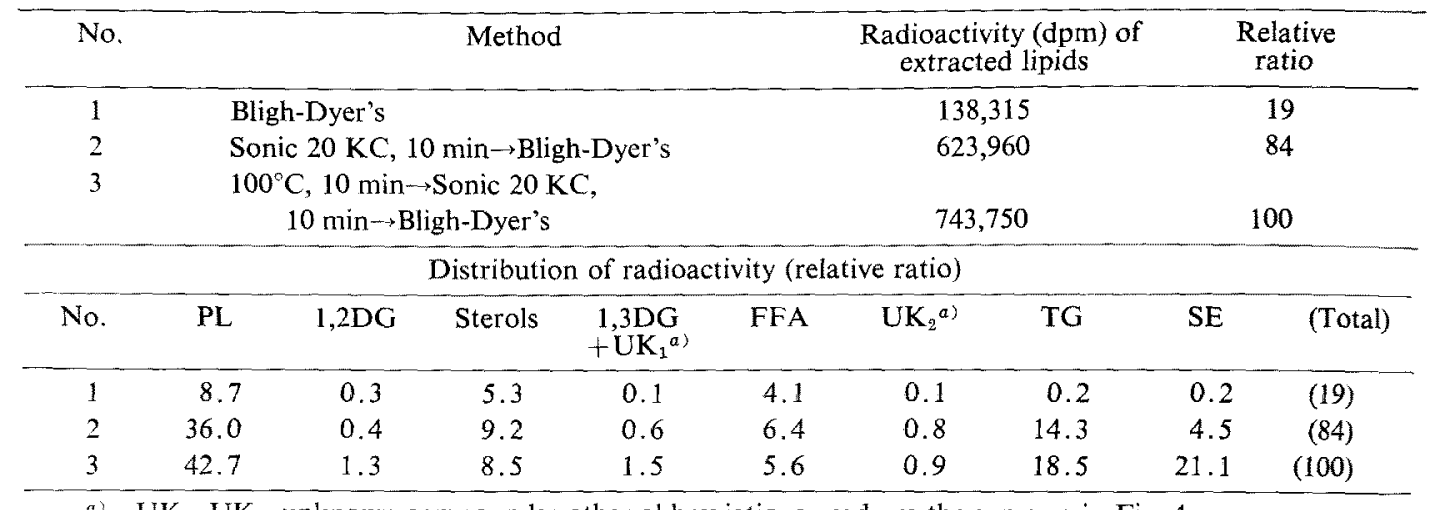

a) $\mathrm{UK}_{1}, \mathrm{UK}_{2}$, unknown compounds; other abbreviations used are the same as in Fig. 4.

extraction method described by Bligh and Dyer. ${ }^{7}$ As shown in Table I, bulks of sterols and free fatty acids and a part of phospholipids were extracted from intact cells of $S$. cerevisiae by direct extraction with organic solvents by Bligh and Dyer's method, whereas triglycerides and sterol esters were only scarcely extracted. However, it was found that the sufficient extraction of lipids from a small amount of cell suspension was obtained by sonication after heat treatment of cells, followed by Bligh and Dyer's method (Table I).

$S$. cerevisiae was grown to late exponential phase and harvested by centrifugation and washed with $0.25 \mathrm{M}$ acetate buffer $(\mathrm{pH} 4.0$ or 6.0) and suspended in the same buffer. Each $1 \mathrm{ml}$ of the suspension was transferred to capped test tubes and autolysis under $30^{\circ} \mathrm{C}$ was initiated by additions of toluene $(0.1 \mathrm{ml})$ and cysteine $(4 \mathrm{mg} / \mathrm{ml})$ to each tube. At zero time, and after prescribed intervals, $0.1 \mathrm{ml}$ of each incubation mixture was removed and diluted with distilled water. A part of the diluted sample was used for the absorbance estimation of autolysis (optical density, $660 \mathrm{~nm}$ ) and the remainder was immediately centrifuged at $2000 \times g$ for $5 \mathrm{~min}$, and the absorbances of the supernatant at 260 and $280 \mathrm{~nm}$ were measured as the indicater of cell injury.

Changes in optical densities at 660,260 and $280 \mathrm{~nm}$ during the initial stage of tolueneinduced autolysis are shown in Fig. 1. The

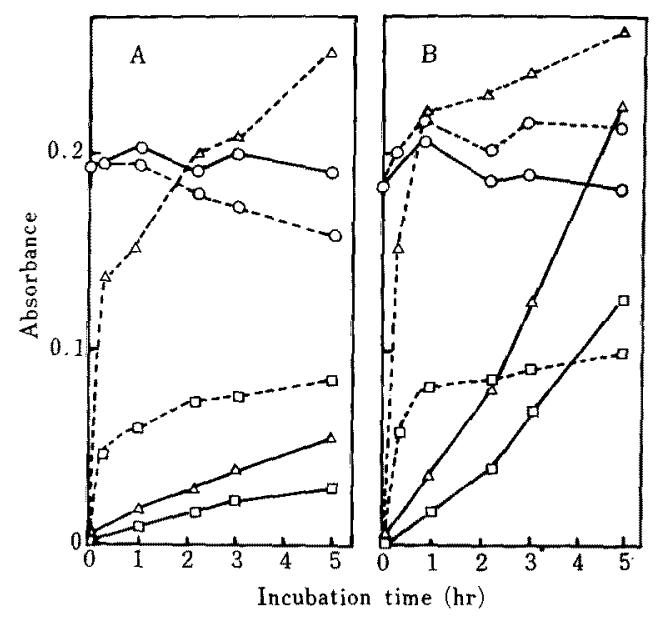

FIG. 1. Toluene-induced Autolysis of $S$. cerevisiae. A, pH 6.0 (0.25 M acetate buffer); B, pH $4.0(0.25 \mathrm{M}$ acetate buffer); _-, cell suspension (control); -----, cell suspension + toluene-cysteine, and the same applies to Figs. 2 and 3 . O, OD $660 \mathrm{~nm} ; \square$, OD $280 \mathrm{~nm} ; \triangle$, OD $260 \mathrm{~nm}$.

remarkable release of UV absorbing substances occurred within $20 \mathrm{~min}$ in the presence of toluene and cysteine. However, when the $\mathrm{pH}$ of the incubation medium was 4.0 (Fig. 1B), the amounts of released UV absorptive substances from cells incubated without toluene and cysteine (control cells) increased gradually with time and after $5 \mathrm{hr}$ incubation, reached up to those from cells with toluene and cysteine, whereas at pH 6.0 (Fig. 1A), such remarkable release from control cells did not occur. 


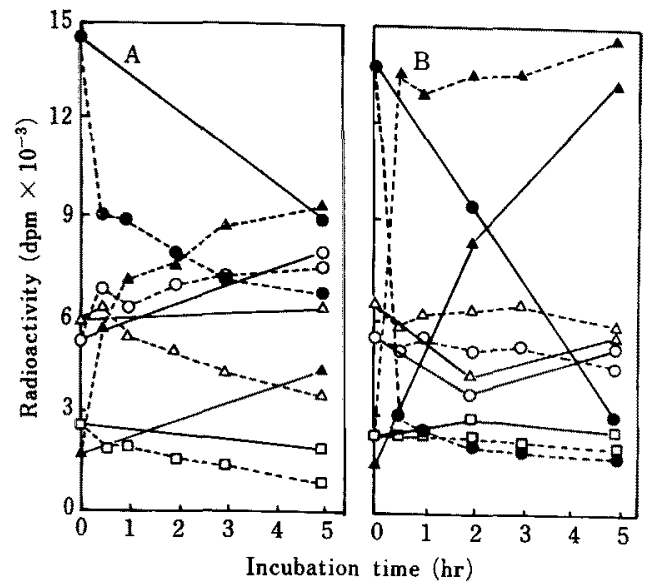

Fig. 2. Changes of Radioactivity of Lipids in ${ }^{14} \mathrm{C}$ labeled Cells during Incubation.

, phospholipids; $\wedge$, free fatty acids; $O$, triglycerides; $\square$, sterols; $\triangle$, sterol esters.

Changes of radioactivity in lipid components of cells during such incubation experiments are shown in Figs. 2 and 3. As shown in Fig. 2A, a decrease in radioactivities of phospholipid, sterol and sterol ester fractions and a concomitant increase in those of free fatty acid and triglyceride fractions were observed during toluene-induced autolysis at $\mathrm{pH}$ 6.0. Whereas, at pH 4.0 (Fig. 2B), a conspicuous decrease of radioactivity in phospholipid fraction was almost proportionate to the increase in free fatty acid fraction, but in the other lipid components, insignificant changes of radioactivity were observed. The same tendency but in less extent was observed in the case of control cells.

Changes of radioactivity of phospholipid components during the incubation were also examined (Fig. 3). Decrease of radioactivity of phospholipid components in toluene-induced autolysate was significant and, after $5 \mathrm{hr}$ incubation at $\mathrm{pH} 6.0$, radioactivity of phosphatidylinositol, phosphatidylethanolamine and phosphatidylcholine reduced to $18,35,31 \%$ of the initial activity, respectively. On the other hand, at $\mathrm{pH} 4.0$ (Fig. 3B), radioactivity of phosphatidylinositol, phosphatidylethanolamine and phosphatidylcholine decreased strikingly to 28,12 and $6 \%$ within $30 \mathrm{~min}$ incubation, respectively, and those in control ex-

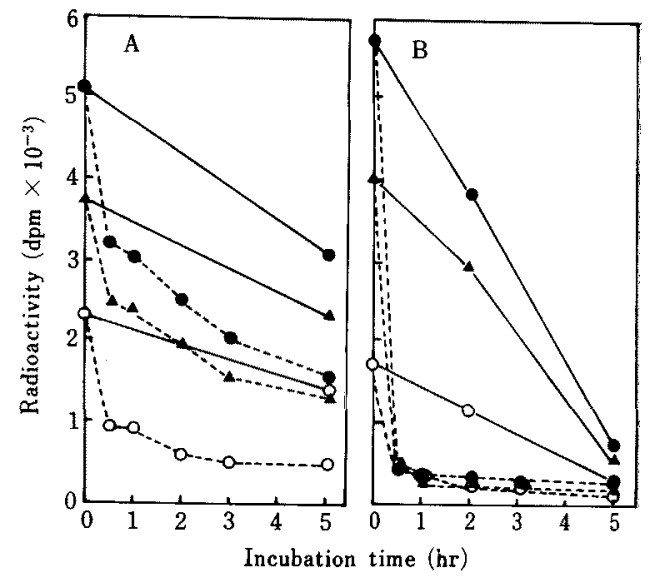

FIG. 3. Changes of Radioactivity of Phospholipids in ${ }^{14} \mathrm{C}$-labeled Cells during Incubation.

-, phosphatidylcholine; 0 , phosphatidylinositol (+ phosphatidylserine); $\Delta$, phosphatidylethanolamine.
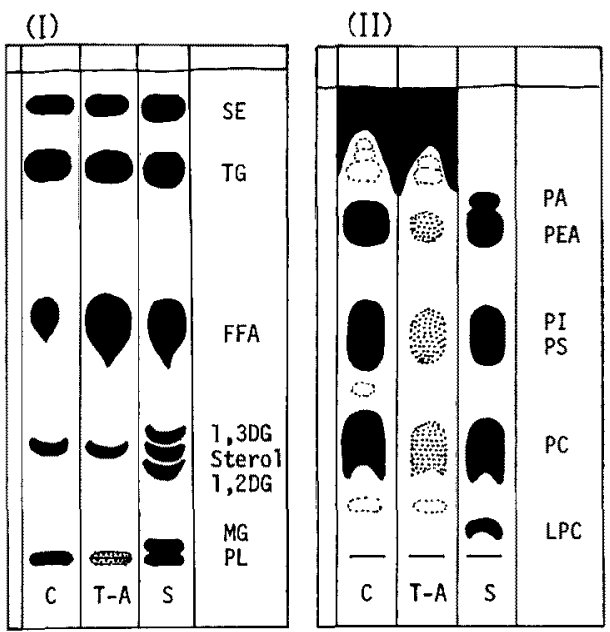

FIG. 4. Representation of Thin-layer Chromatograms of Lipids of $S$. cerevisiae.

Solvent system: (I), petroleum ether-diethyl etheracetic acid (80:30:1, by vol.); (II), chloroformmethanol-acetic acid-water (25:15:4:1, by vol.). C, lipids extracted from control cell suspension; T-A, lipids extracted from toluene-induced autolysate (pH 4.0, $30 \mathrm{~min}$ ); S, standard compounds. SE, sterol esters; TG, triglycerides; FFA, free fatty acids; 1,3DG, 1,3-diglycerides; 1,2DG, 1,2-diglycerides; MG, monoglycerides; PL, phospholipids; PA, phosphatidic acid; PEA, phosphatidylethanolamine; PI, phosphatidylinositol; PS, phosphatidylserine; PC, phosphatidylcholine; LPC, lysophosphatidylcholine.

periments reduced gradually to 16,13 and $7 \%$ after $5 \mathrm{hr}$ incubation. 
As shown in Fig. 2, the total of radioactivities of lipid components did not change significantly during the incubation. Figure 4 is a shematic representation of thin-layer chromatograms of lipids from toluene-induced

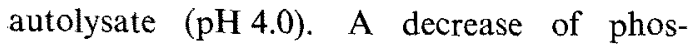
pholipid content and an increase of free fatty acid content (Fig. 4A), and a significant de-

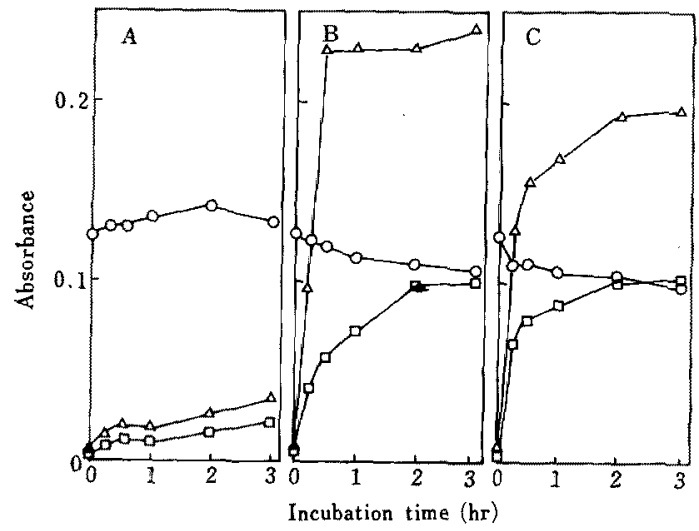

FIG. 5. Organic Solvent-induced Autolysis of $S$. cerevisiae.

A, cell suspension ( $0.25 \mathrm{~m}$ Tris- $\mathrm{HCl}$ buffer, $\mathrm{pH} 6.5)$;

$\mathrm{B}$, cell suspension $(0.25 \mathrm{M}$ Tris- $\mathrm{HCl}$ buffer, $\mathrm{pH} 6.5)$ +toluene-cysteine; $\mathrm{C}$, cell suspension $(0.25 \mathrm{M}$ Tris$\mathrm{HCl}$ buffer, $\mathrm{pH} 6.5$ ) +ethyl acetate, and the same applies to Fig. 6.

O, OD $660 \mathrm{~nm} ; \mathrm{d}$, OD $280 \mathrm{~nm} ; \triangle$, OD $260 \mathrm{~nm}$.

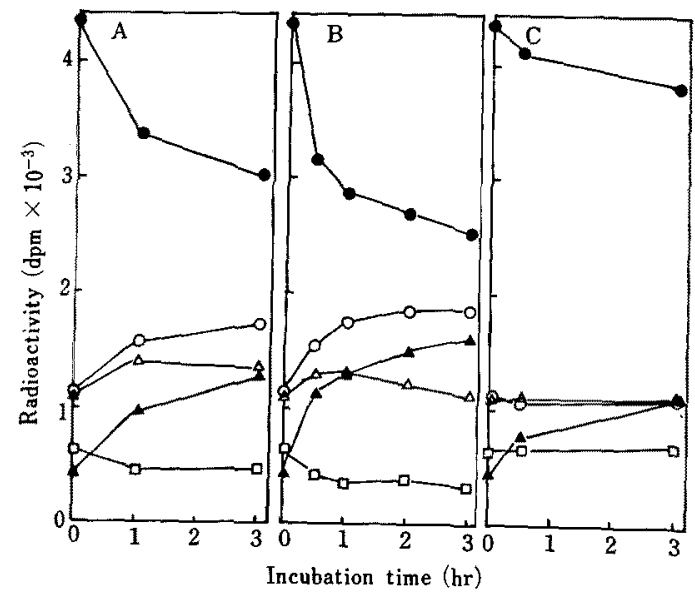

FIG. 6. Changes of Radioactivity of Lipids in ${ }^{14} \mathrm{C}$ labeled Cells during Organic Solvent-induced Autolysis.

$\boldsymbol{0}$, phospholipids; $\boldsymbol{\Lambda}$, free fatty acids; 0 , triglycerides; $\square$, sterols; $\triangle$, sterol esters. crease of each phospholipid component(Fig.4B) were observed. Therefore, it was concluded that deacylation of phospholipids was involved in the early phase of toluene-induced autolysis.

Ethyl acetate is also used to induce plasmolysis of yeast cells. ${ }^{\text {e.g.4,15 }}$ Figure 5 shows the time-course for the early phase of autolysis induced by ethyl acetate comparing with that by toluene. Ethyl acetate was also effective in increasing the initial rate of release of UV absorbing substances from cells. However, as shown in Fig. 6, changes in lipid composition during the incubation were smaller than those of control cells.

\section{DISCUSSION}

Hoffman-Ostenhof et $a l^{103}$ reported the presence of phospholipase $C$ activity in aqueous extracts from dried yeast and Harrison and Trevelyan ${ }^{17)}$ also concluded the break-down of phospholipids on drying yeast was brought about by phospholipase $C$, whereas Van den Bosch et al. ${ }^{18\rangle}$ were unable to detect phospholipase $\mathrm{C}$ activity in dried yeast extracts. On the other hand, phospholipase $\mathrm{A}^{19,20}$ and lysophospholipase ${ }^{18)}$ activity were also detected in yeast and the latter activity was shown to locate in plasma membrane fraction. ${ }^{21)}$ It was found in the present study that remarkable deacylation of phospholipids by intracellular phospholipase(s) was observed at the early phase of toluene-induced autolysis in yeast cells and the rate of degradation of phospholipids was almost correlative to the rate of injury of cytoplasmic membrane estimated by leakage of UV absorbing substances. The increase of free fatty acid content was almost equivalent to the decrease of phospholipids especially when the $\mathrm{pH}$ of the incubation mixture was 4.0 , and recognizable appearances or increases of diglycerides, phosphatidic acid and/or lysophospholipids did not occur in all cases. These results suggest that phospholipase $\mathrm{A}+$ lysophospholipase, the latter activity might be much stronger than the former under these conditions, or phospholipase B might be involved in the degradation of phospholipids 
during toluene-induced autolysis, but not phospholipase C and D.

Letters $^{20)}$ reported the changes of phospholipid composition when baker's yeast was treated with ethyl acetate at $37^{\circ} \mathrm{C}$ for $5 \mathrm{hr}$, which was attributed to stimulation of breakdown of phospholipids by this organic solvent. Arnold $^{22)}$ also found that ethyl acetate-treated cells of baker's yeast were depleted in phospholipid. However, the results depicted in Fig. 6 suggest that ethyl acetate rather inhibits phospholipase activity at least under the reaction condition tested.

\section{REFERENCES}

1) J. F. Lenney, J. Biol. Chem., 221, 919 (1956).

2) K. Myrback and W. Schilling, Enzymologia, 29, 306 (1965).

3) K. Myrback, Arkiv Kemi, 24, 471 (1965).

4) B. Hagihara, T. Horio, J. Yamashita, M. Nozaki and K. Okunuki, Nature, 178, 629 (1956).

5) S. Iguti, Plant Cell Physiol., 9, 573 (1968).

6) W. N. Arnold, J. Bacteriol., 109, 949 (1972).

7) E. G. Bligh and W. J. Dyer, Can. J. Biochem. Physiol., 37, 911 (1959).

8) M. Noda and R. Ikegami, Agric. Biol. Chem., 30,
330 (1966).

9) J. C. Dittmer and R. L. Lester, J. Lipid Res., 5, 126 (1964).

10) H. Wagner, L. Hörhammer and P. Wolf, Biochem. Z., 334, 175 (1961).

11) H. K. Mangold, J. Am. Oil Chem. Soc, 38, 708 (1961).

12) H. Okuyama and S. J. Wakil, J. Biol. Chem., 248, 5197 (1973).

13) J. B. M. Rattray, A. Schibeci and D. K. Kidby, Bacteriol. Rev., 39, 197 (1975).

14) T. Suzuki, A. Takigawa and K. Hasegawa, Agric. Biol. Chem., 37, 2653 (1973).

15) W. N. Arnold, J. Bacteriol., 112, 1346 (1972).

16) O. Hoffman-Ostenhoff, M. Geyer-Fenzl and E. Wagner, "The Enzymes of Lipid Metabolism," ed. by P. Desnuelle, Pergamon Press, Oxford, 1961, p. 39.

17) J. S. Harrison and W. E. Trevelyan, Nature, 200, 1189 (1963).

18) H. Van den Bosch, H. M. Van der Elzer and L. L. M. Van Deenen, Lipids, 2, 279 (1967).

19) R. Kokke, G. J. M. Hooghwinkel, H. L. Booij, H. Van den Bosch, L. Zelles, E. Mulder and L. L. M. Van Deenen, Biochim. Biophys. Acta, 70, 351 (1963).

20) R. Letters, Bull. Soc. Chim. Biol., 50, 1385 (1968).

21) T. Nurminen and H. Suomalainen, Biochem. J., 118, 759 (1970).

22) W. N. Arnold, J. Biol. Chem., 247, 1161 (1972). 